\author{
Svetlana M. Strugarević* \\ Univerzitet u Beogradu \\ Filološki fakultet \\ studentkinja doktorskih studija
}

https://doi.org/10.18485/analiff.2018.30.1.5 821.411.21.09-1 Ахјалија Л.

Originalni naučni rad

Primljen: 02.01.2018. Prihvaćen: 05.05.2018.

\title{
LEJLA EL AHJALIJA
}

Lejla el Ahjalija (Laylā al-'Ahyaliyya') je jedna od najpoznatijih i najvažnijih pesnikinja u klasičnoj arapskoj poeziji. Pripada omajadskom periodu a o njenom pesničkom umeću govori i veoma ugledan položaj koji je imala na halifskom dvoru. Najbolje se pokazala u ljubavnoj poeziji i tužbalicama ali je pisala i druge žanrove dok je u legendu ušla zbog tragične ljubavi prema Taubi ibn el Humajiru (Ṭawba bin al-Humayyir). Istakla se i po svojoj rečitosti, hrabrosti, inteligenciji i zadivljujućoj lepoti. Uprkos tome što je pominju i navode njenu poeziju mnogi kritičari i istoričari književnosti $i$ što građe za njeno proučavanje ne manjka, Lejla el Ahjalija je slabo poznata širim krugovima ili bar mnogo manje poznate od el Hanse (al- $\underline{H} a n s \bar{a})$. I ščitavanjem raznih pregleda klasične književnosti, brojnih anegdota i divana pesnikinje, nastao je ovaj kratak pregled njenog života i prevod nekoliko pesama u nadi da će ih biti još. Interesovanje za ovu pesnikinju može probuditi i želju za proučavanjem mnogih drugih pesnikinja u klasičnoj arapskoj književnosti čiji je broj mnogo veći nego što se očekuje, a njihovo umeće i teme kojima se bave mogu da pariraju i da se nadmeću sa njihovim daleko poznatijim muškim savremenicima. Pored upoznavanja sa njihovom poezijom, za nas bi bilo korisno i oslobađanje od predrasuda koje postoje o arapskom svetu, islamu i položaju žene u njemu.

Ključne reči: Laylā al-'Ahyaliyya, Țawba bin al-Ḥumayyir, klasična arapska poezija, omajadska književnost, arapske pesnikinje, uzritski gazal, ritāa', madīh, al-Hağğăğ bin Yūsuf at-Taqafī

Laylā bint 'Abdullah bin al-Ruḥhāl bin Šaddād bin Ka'b bin Mu'āwiya al-'Ahyal' bin 'Ubād bin 'Aqīl iz plemena Ka'b bin Rabī a bin

* $\quad$ svetlanastrugarevic90@gmail.com

1 U tekstu je korišćena ZDMG transkripcija. Imena koja se pominju više puta prilagođena su srpskom izgovoru, a uz prvo pominjanje data je transkripcija u zagradi.

2 'A hyyāl (ar.) znači orao, soko, žuna 
'Āmir bin Șa‘ṣa‘a (Farūḥ, 1981: 515) ili kraće Lejla el Ahjalija je jedna od najvećih pesnikinja u klasičnoj arapskoj književnosti koju je, po nekim mišljenjima, jedino el Hansa nadmašila u slavi. Ne zna se tačna godina njenog rođenja, a i o godini smrti postoje razni podaci, no, sa sigurnošću se zna da je pripadala omajadskom periodu. Njeno pleme je bilo čuveno po svom junaštvu i među prvima je primilo islam i pomagalo u širenju nove vere (Šahīdu-1-'Islām, 2008). Pored toga su ostali upamćeni i po svojim velikim ljubavima koje su ušle u legendu i koje su opevane u pesmama (Šahīdu-1-'Islām, 2008). Iz tog plemena je i Qays bin Mulawwaḥ, čuveni Medžnun (Mağnūn; Al-Fāhūūī, 1986: 426). Lejla se istakla po svojoj rečitosti, pesničkom umeću, hrabrosti, inteligenciji i zadivljujućoj lepoti.

Odrasla je uz svog brata od strica Taubu ibn el Humajra (Tawba bin al-Humayyir) koji je takođe bio pesnik prefinjenih osećanja (Šahīdu-1'Istām, 2008) iz plemena Aqīl bin 'Āmir; Zaydān, 1958: 345). Između njih se rodila velika ljubav koja je do kraja njihovih života ostala čedna, platonska ili uzritska ljubav kakve su bile i ljubavi Medžnuna i Lejle (Mağnūn wa Layla), Džemila i Butejne (Ğamīl wa Butayna), Kajsa i Lubne (Qays wa Lubnā) i Antare i Able ('Antara wa 'Abla) ${ }^{1}$ i podjednako nemoguća i sprečena delovanjem njihovih saplemenika. Pored poezije koje su nesrećni ljubavnici ostavili za sobom, postoji i veliki broj legendi koje su se prenosile u narodu ne dozvoljavajući da se plamen tragične ljubavi ugasi. Tauba je jednom prilikom video Lejlu gde sa drugim ženama dočekuje muškarce iz pohoda i tada ga je posebno očarala (Diwān Layla al-'Ahyāliyya, 2013). Ljubav između njih je rasla, poezija koju su posvećivali jedno drugom se pročula među plemenima, a legenda o njima je izgleda još u to vreme oživela. Tauba je zatražio ruku voljene od njenog oca, ali on je, kako priča kaže, odbio to jer bi dozvola potvrdila postojanje neprihvatljivih veza između njih pre braka o kojima se govorkalo među plemenima. Da bi

1 Jedan od najčuvenijih pesnika koji je, navodno, poludeo od ljubavi i dobio nadimak Medžnun (Ludak) je živeo u 7. veku, a njegovu ljubavnu priču Lord Bajron naziva Romeom i Julijom sa Istoka. Lejla za kojom on pati, naravno, nije pesnikinja Lejla el Ahjalija. Ğamī̄ bin Ma'amar je takođe bio pesnik koji je živeo u osmom veku i pripadao je plemenu Uzrita ili Azra, ,što za ljubav glavu gube i umiru kada ljube“, a njegova draga se zvala Butejna ili Busejna. Ljubav između Kajsa i Lubne je opisao 'Abū al-Farağ al-Ișfahāni u svojoj Knjizi pesama (Kitāb $a l-A \dot{g} \bar{a} n \bar{l})$, a veliku ljubav između preislamskog pesnika Antare i njegove Able je opevao al-'Așma‘ī , jedan od pesnika na dvoru Haruna el Rašida. 
ugušio glasine, udao ju je za čoveka iz plemena al-Adla' ${ }^{2}$ ali brak nije sprečio Tauba da je posećuje (Šahīdu-l-'Islām, 2008). Mada su te posete bile prijateljskog karaktera, pleme se žalilo sultanu koji je dozvolio da se Tauba ubije ako joj opet dođe. Jednom prilikom je krenuo u običajeno vreme, a Lejla je znajući za ovu dozvolu izašla pred njega bez vela što je kod njega izazvalo sumnju pa je on odustao od posete spasivši se na taj način. Nastradao je u jednom od svojih pljačkaških pohoda kada ga je ubilo pleme 'Awf jer im je ukrao kamile (Šahīdu-l-'Islām, 2008). Po narodnoj priči Lejla je za to saznala tek kada je videla Taubin grob pored puta kojim je išao njen karavan i rešila je da ga poseti mada je njen muž bio protiv toga. Uporna u svojoj odluci, sišla je sa kamile, prišla je grobu i rekla: „Selam alejk, Tauba“, zatim se vratila svojoj pratnji i gorko zaplakala jadajući se da nije znala da je Tauba lažov. Ovo je sve začudilo pa su je pitali za objašnjenje. ,O, zar on nije rekao ${ }^{3}$ :

Kad bih pod zemljom ispod grobne ploče bio Ili bih joj ja radosno otpozdravio Jer želim Lejli i ono što od mene nije a Lejla el Ahjalija mi tada selam nazvala ili bi se sova sa mog groba krikom odazvala ako bi se tom dobru njena duša radovala

Zašto mi onda ne odgovori kako je obećao (Diwān Layla al'Ahyāliyya, 2013)?" U tom trenutku je jedna sova prhnula iz blizine groba pravo u lice kamili koja se uznemirila i povredila Lejlu udarivši je u glavu i ona pade na zemlju mrtva. To se desilo 85/704. ili 86/705. godine u oblasti koja se zove al-Rayy (Šahīdu-1-' Islām, 2008). Tu je sahraniše pored voljenog Tauba gde bar u smrti ostaše večno zajedno.

Ovaj legendarni kraj, prožet magičnim relaizmom i igrom sudbine, je zaista lepo zaokružio tragičnost velike i nesrećne ljubavi, ali tu je, nažalost, i druga, ne tako romantična, verzija koja objašnjava brojne tužbalice za Taubom. Po ovoj verziji, Lejla je ubrzo po Taubinoj pogibji saznala da je ostala bez dragog zbog čega se povukla u samoću, neutešno pakala i opevavala njihovu ljubav bolno tužeći za njim. Prvi muž se razveo od nje, ili po drugoj

2 Kao al-Adla 'se navodi kod Farūh̄a (1981:515), al-Fāhnūrīja (1986: 426) i Zaydāna (1958: 345), kao al-Aḍla ' kod Šahīdu-l-'Islāma (2008) i čak kao al-Aḍlag kod aș-Șamaḍa (1998: 9).

3 Stihovi se ne čitaju po kolonama već po redovima kao polustihovi. Ovakvim načinom ispisivanja stihova imalo se za cilj prikazivanje oblika, strukture i rime klasične arapske pesme (ili, u ovom slučaju, odlomka). 
verziji umro od ljubomore, pa su je ponovo udali. Njen drugi muž je bio Sawār bin 'Ūfī al-Qušayrī sa nadimkom 'Ibn al-Hayā, pesnik muhadramun' i jedan od ashaba $^{5}$ sa kojim je, kažu, izrodila mnogo dece (Šahīdu-l-'Islām, 2008). 'Abū Bakr Muhammad bin Dāwūd al-Ẓāhirī u prvom delu svoje knjige Kitāb az-Zahra ${ }^{7}$ smatra da je Lejla poznavala ljubav samo delimično i da je ljubav nikada nije potpuno obuzela, jer da ga je zaista volela, posle Taubine smrti ni njoj ne bi bilo do života (Farūh, 1981: 515). Jednom prilikom je od el Hadžažda ibn Jusufa el Takafija (al-Hağğăğ bin Yūsuf al-Taqafĩ) tražila da je pošalje u Horasan kod Kutejbe ibn Muslima (Qutayb bin Muslim) što je ovaj odobrio, ali je umrla usput. Ako se ovoj priči veruje, Lejla je umrla između 86/705. godine kada je Kutejb osvojio Horasan i 95/713. kada je umro el Hadžadž, dakle negde oko 90/709. godine, i veruje se da je nadživela Tauba za skoro deset godina (Farūh, 1981: 516).

Što se tiče Lejline poezije, ona je dosta prisutna u književnim kritikama i pregledima klasične arapske književnosti i pored el Hanse je najviše citirana. Stariji kritičari i tumači poezije često ističu da je ona prevazišla najveći broj svojih muških savremenika. Njeno ime se pominjalo i na plemenskim većima istkanutih Kurejša ${ }^{8}$, a i mnogi pesnici su istakli njenu poeziju kao najbolju i omiljenu. Među njima su al- Farazdaq ${ }^{9}$ koji je voleo i cenio Lejlu, 'Abū Nuwās koji je znao napamet više njenih pesama, 'Abū Tammām koji navodi primere njene poezije u svojoj knjizi (Šahīdu-l'Islām, 2008), al-' Așma ‘i koji joj je davao prednost nad el Hansom (Farūḩ, 1981: 516), 'Abū al- 'Abbās al-Mubarrad i 'Abū al-'Alā' al-Ma 'arī.

Njena poezija je ženska, tanana, emotivna i iskrena ali na čvrstim tradicionalnim temeljima, poznata je po doteranosti i energičnosti izraza, bogatom rečniku, ali i pitkosti i lakoći i muziklanosti. Često je koristila antitezu. Ako se uporedi sa el Hansainom, može se primetiti da je

$4 \quad$ Naziv za pesnike prelaznog perioda tj. one koji su živeli i stvarali i pre i posle pojave islama.

5 Od arapske reči șahāāba što doslovno znači „drug, saputnik, pratilac“; drugovi i saradnici Proroka Muhameda.

6 U originalu stoji 'Abū Bakr Muḥammad bin 'Abī Sulaymān al-'Așfahānī̄; reč je o srednjovekovnom teologu i učenjaku koji je živeo između 255/868. i 279/909. godine.

$7 \quad$ Knjiga cveta je 'Ibn Dāwūdovo delo sa kraja IX veka nastalo u Bagdadu. Smatra se prvom knjigom o teoriji ljubavi na arapskom jeziku.

8 Qurayš je arapsko pleme koje je nastanjivalo prostor oko Meke. Oni se smatraju čuvarima Kabe, izvode svoje poreklo od Avrama (Abrahama), a pripadnik ovog plemena je bio i poslanik Muhamed.

9 Al-Farazdaq ili Hamām ibn Ġālib je arapski pesnik iz 7. veka. 
el Hansaina poezija gotovo oslobođena mašte i poslovica, ograničena je jednom temom uz ponavljanje prizora i izraza dok Lejlina poezija obiluje temama, motivima i izrazima, a poznat je njen doprinos u poslovicama i izrekama (Šahīdu-1-'Islām, 2008). Takođe je kao ličnost bila snažnija od el Hanse i zahtevala je poštovanje koliko ga je i ukazivala. Najpoznatija je po ljubavnim stihovima, uzritskom gazelu ${ }^{10}$, i po tužbalicama ${ }^{11}$ za Taubom. Ispevala je i tužbalicu za halifom Uțmānom bin Affānom (Farūḩ, 1981: 517), zatim mnoge medihe ${ }^{12}$ ili hvalospeve (na primer za al-Hadžadža), junačke ili epske ${ }^{13}$ pesme, hvale za svoje pleme iskazujući u njima svoj $\operatorname{ponos}^{14}$, na primer opis bitke između njenog plemena i plemena Madhig ${ }^{15}$ i Hamdān ${ }^{16}$ ( Šahīdu-l-' Islām, 2008), a između nje i al-Nābig̉e al-Ğa 'diyye je bilo satire ${ }^{17}$. (Al-Fāhūūrī, 1986: 426).

Zbog svog pesničkog umeća, Lejla el Ahjalija je imala ugledno i značajno mesto u društvu, plemenu ali i na dvoru kod halifa, prinčeva $\mathrm{i}$ guvernera. Izlazila je pred halifu Muaviju ibn Abi Sufjana ( $\mathrm{Mu}$ 'āwiya bin 'Ab̄̄ Sufyān; Šahīdu-l-' Islām, 2008), Abdulmelika ibn Marvana ('Abd al-Malik bin Marwān) i upravitelja Iraka El Hadžadža (Farūh, 1981: 516). Slušali su je dok je kazivala hvalospeve njima ali i dok je žalila za Taubom i opevavala njihovu ljubav i zato je dobila svakojake nagrade. Jednom prilikom ju je el Hadžadž darovao sa 500 dirhema, 5 haljina i 5 kamila (Šahīdu-1-'Islām, 2008). O ovim susretima i razgovorima sa Lejlom postoje brojne anegdote koje često govore o Lejlinoj dovitljivosti, hrabrosti, slobodi pred vladarima, njenoj smelosti i samouverenosti. Jedna od njih je:

\section{LEJLA EL AHJALIJA KOD EL HADŽADŽA}

Jednom je tako el Hadžadž bio u medžlisu i sa njim Utba ibn Said kad je ušao vratar i rekao: „Gospodaru el Hadžadže, na vratima je žena koja traži dozvolu da uđe."

10 Ġazal - ljubavna pesma; može biti beduinska, uzritska, čedna ili platonska i gradska ili erotska

11 Ritāa

12 Madīh

13 Ḥamāsa

14 Fahr

15 Poznato i veliko arapsko pleme iz oblasti Jemena

16 Pleme iz Jemena, a kasnije ime saveza koji su činila plemena Hamdan, Bakil i Hašid

17 Hig̀a $\bar{a}^{\prime}$, muhāgàa 
„Koja žena?““

„Neće da kaže ime. Ali ona je...“

„Ona je šta? Reci, vrataru.“

„Ona je mnogo lepa, gospodaru.“

„Šta čekaš? Uvedi je odmah.“

Lejla el Ahjalija je ušla i sa njom dve njene sluškinje, a el Hadžadž je skrenuo pogled i spustio glavu. Lejla mu se približila i sela preko puta. Kada je podigao pogled, zadivio se tolikom lepotom.

„Ko si ti?"“

„Zar me ne poznaješ, el Hadžadže? Ja sam Lejla el Ahjalija.“

Kao da ga je njen glas razbudio, on se vrati sebi i seti se svoje moći.

„Ti si Lejla el Ahjalija, pesnikinja?“

„Da. Ja sam ta.“

„Šta te dovodi, o Lejla, na naš medžlis?““

„U zvezdama lažni znaci, brojem manji sve oblaci, zima što se približila i nevolja umnožila. A prva nam je posle Božje tvoja pomoć uvek bila.“

„Dobrodošla, pesnikinjo slavna. Deder, opiši nam ti, Lejla, krjajeve iz kojih si došla.“

„Prah umesto puteva, zemlja posta jalova, međ' narodom pometenost, nada im je tvoja milost, godine nas pristigoše, ništa dobro ne doneše, imetak nam ugrabiše, ljude svukud rasturiše i čeljad nam svu pobiše."

„Dosta je, Lejla. Dakle ovo je tvoja proza. A kakva ti je poezija?“

„Da li želiš da čuješ šta sam o tebi spevala, o emire?“

„Izvoli, Lejla. Da čujem.“

„Kažem, emire:

O, Hadžadže, nek' te ne izneveri oružje mada je u Božjoj moći kada i šta biva

O, Hadžadže, ne predaj se pobunjenom, a ni Bog mu ne d'o o čem' sniva Kad se el Hadžadž obolele zemlje lati, taj izleči svakog živa

Izleči od bolesti teške, pa ko mladić koplje baca te ga onda i zaliva

Zaliva ga i napija bujicama krvi ljudske dok s' poseda se nova sliva

Promeni se el Hadžadžovo držanje i na licu mu se ukaza bes, onda se okrenu ka Utbi ibn Saidu i šapnu mu: „Ubio je Bog, ni jedan me pesnik ne opisa tačnije od nje od kako sam došao u Irak.“ Onda se okrenu njoj govoreći: „Dovoljno je.“

„Ali ja još nisam završila.“ 
„Dovoljno je, Lejla. Mladiću, vodi je kod našeg prijatelja i reci mu da joj zapuši usta."

Lejla je hodala sigurno i samouvereno iza mladića ubeđena da je bila dobra i da će dobiti nagradu od emira uprskos tome što je čula el Hadžadža kako naređuje mladiću da je odvede do čoveka koji će joj zapušiti usta. Kada su stigli do tog čoveka, mladić reče:

„Gospodar el Hadžadž ti je poručio da odsečeš jezik ${ }^{18}$ ovoj ženi.“

Čovek je stao da priprema oštar nož ne bi li obavio el Hadžadžovo naređenje, kad Lejla vrisnu na njega:

„Crk’o majci! Ču li ti šta je mladić rekao? El Hadžadž je naredio da mi zapušiš usta poklonima i darovima.“

Čovek je stao zbunjen i ne znajući šta da radi, otišao je kod el Hadžadža lično da se uveri u ispravnost naređenja koje mu je doneo mladić. El Hadžadž se naljuti i umalo ne otseče jezik tom čoveku ali se smiri i reče:

„Vratite je ovamo.“

Lejla se vratila podjednako samouverena i sigurna do el Hadžadža koji reče: „Umalo ne napraviše grdnu grešku.““

A ona ispeva sledeće:

„O, Hadžadže, iznad tebe niko nije sem halife i milosti Božje same

O, Hadžadže, ti si junak u ratu kad bukne i za narod svetlo usred tame.“

Onda se el Hadžadž okrenu ovima što su sedeli sa njim da mu kažu svoje mišljenje o njoj, a Utba ibn Said reče: „,Tako nam Boga, ne videsmo nikoga čistijeg jezika, boljeg govora, veće lepote i čvršćeg stiha." (Al-Kan ānī, 2013a)

Ipak, najbolji pokazatelj Lejline pesničke veštine je sama poezija. Jedan od problema klasične poezije se javlja i u Lejlinim divanima, a to je prenošenja u dužem vremenskom periodu (usmenom i pismenom) što je dovelo do postojanja nekoliko verzija istog stiha, drugačijeg rasporeda stihova i polustihova i tome sličnog. U divanu iz 1998. godine su pesme raspoređene po rimi i pored tumačenja slabije poznatih reči u komentarima se navode i razne verzije stihova i njihovi izvori, a prepevani stihovi su izabrani iz tog izdanja.

18 Igra rečima. Ova fraza na arapskom može da znači „odseći jezik“ ali i ,zapušiti i zatvoriti usta“. 


\section{LEJLA HVALI SVOJE PLEME}

Mi smo od plemena el Ahjal, našmladić i sa štapom ${ }^{19}$ svoju slavu vešto brani

Kopljad tužna jadikuju ostanu li uz samare, a po darežljivosti mi smo znani

Jogunasta sablja zna da po žeđi sestra nam je jer izlomljena kost je hrani

Čvršći smo od vas u grudima žena vaših kad zaori se vapaj rani ${ }^{20}$ (Aṣ-Ṣamaḍ, 1998: 39)

\section{TUŽBALICA ZA TAUBOM}

Zakleh se da oplakaću Tauba da za sve mrtve po suza kane Života ti, čega da se mrtav stidi koji za života nema mane Nema živog i najzdraviji da je da nadživi onog što u grobu leži Oduvek je bilo da strpljiv je onaj kome dan je muka a ide sve teži Sve mlado i jedro ka truleži grabi i svaki će čovek pred Boga otići

Dvoje što se drže i žive zajedno mogu da odlažu al' rastanak će stići

Bio živ ja li mrtav, o junače, uvek Božja pomoć uz tebe bila Zaklinjem se da plakaću i kleti sve dok ptice poje i imaju krila Nek se pazi ubica iz Aufa, o žalosti, što ne bejah s njima al' me većma plaši drugo pleme što šuruje s Romanima ${ }^{21}$ (Aș-Șamaḍ, 1998: 40)

\section{Literatura}

Al-Fāhuūrī, ㅂ. . (1986). Tārīḥ al-' adab al- 'arabī. Bejrut: Dār al-Ğ̄̄l.

Al-Kan ān̄ī' 'A. (2013a). Al-Muğāhira bi-1- 'ašq: Layla al-' Ahyāliyya wașafat alHağğāăğ fa' amara biqaț i lisāniha: bi-ș-șalla wa-1- ațāà'. 'A ḩbār al-Wațan [on line]. Dostupno preko: https://bit.ly/2I5pOtw [17.11.2013]

19 Kad ostari i služi se štapom

20 Čuvaju i brane žene od nevolja bolje od drugih plemena

21 Lejla strahuje da Tauba nije ubilo pleme Auf nego jedno drugo koje sarađuje sa Vizantincima. 
Al-Kan 'ānī, 'A. (2013b). Layla al-'Ahyāliyya ,„šā iratu-1- 'affāf wa-1-ğur'a“ ğalīsatu-l-hulafă' bilā madḥ wa lā takassub (2). 'Ahboār al-Wațan [on line]. Dostupno preko: https://bit.ly/2rztZTr [17.11.2013]

Aṣ-Șamaḍ, W. (1998). Diwān Layla al-' Ahyāliyyya. Bejrut: Dār Șāḍir

Božović, R. (2012). Istorija arapske klasične književnosti (od 6. do 14. veka). Beograd: Utopija

Diwān Layla al-'Ahyāliyya. (2013). Al-Hakawātī [on line]. Dostupno preko: http://www.al-hakawati.net/arabic/arabpers/poet54.asp [17.11.2013]

Farūh, U. (1981). Tārīḥ al-'adab al-'arabì (tom I). Bejrut: Dār al- 'Ilm li-1-Malāyī.

Muftić, T. (1984). Arapsko-srpskohrvatski rječnik. Sarajevo: Starješinstvo Islamske zajednice u SR Bosni i Hercegovini, Hrvatskoj i Sloveniji.

Šahīdu-1-'Islām, M. (2008). Hiidmāt al-nisā' fī aš-ši 'ar al- 'arabī. Jurnal of Arabic,15. [on line]. Dostupno preko: https://www.academia.edu/453389/_ [17.11.2013]

Zaydān, Ğ. (1958). Tārīḥ 'adab al-lugia al- arabiyya (tom I). Kairo: Dār al-Hilāl. 
Svetlana Strugarević

\section{Summary}

\section{LEJLA EL AHJALIJA}

Layla al-Akhyaliyya is one of the most famous and most important female poets in classical Arabic poetry. She was a famous poet from Umayyad period of Arabic history, and thanks to her brilliant mind and eloquence she had a very prominent position on the Caliph's court. She proved to be best in writing love poetry, elegies and laments, but she also wrote satires and panegyrics. She entered the legend thanks to her tragic love for Tawba b. al-Humayyir. Their love story is included in this paper. Her courage, intelligence and amazing beauty made her famous. Many critics and historians of literature mention and quote her, but she is poorly known out of the scientific cicles, or at least much less known than alKhansa. Using various reviews of classical literature, numerous anecdotes and diwans, this short overview of her life was created, as well as the translation of several songs. Layla al-Akhyaliya could interest scientist to explore other female poets in classical Arabic literature whose number is much higher than expected. They were standing side my side with their well-known male contemporaries.

Key words: Arabic poetry, Lejla El Ahjalija 